\title{
Kapitalist Fırsatçılığa Kurumsal Çözüm Önerisi: Muşaraka Vakfı1
}

\author{
Yusuf Dinç* \\ İstanbul Sabahattin Zaim Üniversitesi
}

Öz

Kapitalizm tüm başarısına rağmen sorunlu bir kurgudur ve krizler üretir. Kapitalist sistem içinde herhangi bir zamanda ve herhangi bir yerde ekonomik kriz yaşayan bireyler, işletmeler, sektörler, bölgeler veya ülkeler bulunabilir. Kapitalizm bu durumu içselleştirmiş ve bir sorun olan krizi firsat olarak sunmuştur. Hatta bu sorundan yararlanan bütün bir sosyoloji ve bu sosyolojinin unsurları olan firsatçılar ve simsarlar üretmiştir. Bu çalışmanın amacı İslam iktisadı perspektifinden kriz literatürünün sistematik bir analizini yaparak kapitalist firsatçlık karşısında çözümün önemli bir bileşeni olabilecek nitelikteki muşaraka vakfı model önerisinin uygulanabilirliğini tartışmaktır. Bulgular kriz fırsatçılığı karşısında çözümün vakıf modeli içerisinde şekillendirilebileceğini göstermektedir. Model önerisi Ahilik tecrübesi üzerine kurulmuştur. Öneri ülke düzeyinde bir politika bileşeni olarak ele alınabilir.

\section{Anahtar Kelimeler}

İslami finans, kriz, kapitalizm, firsatçılık, vakıf, mütevellî

1 Bu makalenin ilk taslakları 2018 yılında İstanbul Sabahattin Zaim Üniversitesi kampüsünde gerçekleştirilen 1st International Waqf Instituiton Symposium'da sunulmuş ve katılımcıların çok değerli tespit ve katkıları dikkate alınarak tamamlanmıştır.

* Doç. Dr., İstanbul Sabahattin Zaim Üniversitesi, İşletme ve Yönetim Bilimleri Fakültesi, İslam Ekonomisi ve Finansı Bölümü, yusuf.dinc@izu.edu.tr, ORCID ID: 0000-0002-5321-2723 


\title{
The Enterprise Solution to Capitalist Opportunism: The Musharakah Waqf
}

\begin{abstract}
Despite all its success, capitalism has a problematic structure that produces crises. Individuals, businesses, sectors, regions or countries can be found in crisis anytime and anywhere in the capitalist system. Capitalism has indigenized this situation and presented the crisis, which is normally a problem, as opportunity. It even produced an entire sociology and its elements: opportunists. This study aims to propose and discuss the feasibility of the musharakah waqf model, which can be an important component of the solution to capitalist opportunism by conducting a critical analysis of the current crisis literature. Findings indicate that the proposed model can be an important part of solution against capitalist opportunism. The basis of the proposed model depends on Ahilik (futuwwa) experience in Anatolia. The proposed model can be considered as a country level policy.
\end{abstract}

\section{Keywords}

Islamic finance, crisis, capitalism, opportunism, waqf, trustee

\section{Extended Abstract}

The interrelation between the capitalism and the crises is critically analyzed in the literature of Islamic economic thought. Many studies are conducted to reveal the inter-dynamics of capitalism that cause crisis.

Capitalism is the theory of toxic growth and has been successful in this. Its basic problem is how it manufactures crises due to ignoring economic values for the sake of growth. Capitalism, which ignores fair distribution, experiences the demand problem, and the system experiences crises in accordance with its flawed nature. Within the capitalist system, individuals, businesses, sectors, regions, or countries can be found experiencing economic crises anytime and anywhere. Keynes transferred this problem to the conjuncture wave theory. Accordingly, the periods of economic boom and boost that followed each other monitor development.

On the other hand, the model that associates capital with interest and increases the impact of the crises when the profitability of investment reaches or falls below market interest rates. Capitalism has internalized this situation, which is normally a problem, and offers it as an opportunity. It even produces opportunists who seek benefit from the problem caused by capitalist paradigm.

Schumpeter (1942: 83) described the economic model as creative destruction. So that, opportunism is considered the basic feature of the model's economic actor definition (Williamson, 1993: 97). Economic actors of Islamic economic thought are considered efficient against capitalist crisis-oriented structure in 
the literature. Besides the applicability of waqf model is discussed from different perspectives for financial and sustainability solutions.

Hasan and Abdullah (2008) showed the waqf model's relationship with developing self-investments and its applicability. Kato (2004), in his study examines the waqf model's historical development, handled the waqf system within the community-oriented model rather than the industry-focused model. His approach is supported through the views of important scholars of Islamic thought. Nevertheless, the waqf model can also be considered successful in each of the two fields.

Schoenvlum (1999) showed capitalist regulations have caused the downfall of waqfs and the rise of trusts (1999). This relationship has been able to effectively push the waqf model outside of the industry and squeeze debates in narrow fields such as microfinance. Yet the waqf model must not be constricted into the form of either industry or society because obviously both individuals and companies may periodically feel the need for waqf services. This relationship can be shown among the reasons why waqfs and waqf-related discussions have spread their way into Western economies as well.

The waqf model, one of the institutional structures of Islamic economics, has a sustainability-focused business concept. The waqf concept can bring a strong alternative to defeat capitalism's opportunism which can be described as ignoble benefit expectation by inspiring from Feriuddin Attar's Pendname. As an Islamic economic institution, waqf has come to the forefront as a social service because of its economic security of ownership (Kuran, 2001). Waqfs organized around the principles of assistance and interdependence have been the drivers of socio-economic well-being in various fields. Babacan (2011), however, showed the waqf model to not just be about acceptance and interdependence; it is an institution that needs to be addressed as an economic actor.

The waqf model can be brought as an enterprise alternative against capitalist opportunism and dirty company brokerage. This waqf model is a structure established on participating as partners using the principle of solidarity in businesses that have difficulty on carrying out their commercial activities. Its nature is of a special kind of trustee who participates in the partnership and is the antithesis of capitalist opportunism. It can be established either as a limited musharakah-waqf through sectorial or regional concentration or as an unlimited musharakah-waqf. It can participate as a partner on the basis of application of firms that experience crisis yet have sustainability. Hassan and Kayed (2009), indicating that partnership-based Islamic finance models can be handled in the face of crises as determinants of enterprise and socio-economic well-being, encouraged proposing a model that prioritizes social welfare in their study.

The proposed waqf model is inspired from Ahi associations of Seljuk and Ottoman times. Ahi associations' ability to act as trustee is based on expertise of 
board. Its board members are selected from those who are generally accepted as masters in the branches of similar professions. In this respect, they possess the ability to provide correct solutions to problems by analyzing the situation of the member in normal crisis (the main difference of capitalist crisis from a normal crisis is its fictitious anomaly character).

The waqf concept proposed employs specialists who have skills on certain areas that perfectly fit to solutions of the controlled businesses problems, such as management, innovation, and finance. So that, businesses sustain their operations, their business partners or industry or region and the employment are secured. To provide assurance to the other businesses that could be negatively impacted by a failure of the applicant is one of the most important motive of the waqf.

The musharakah-waqf concept support sustainability of overall economic environment through its motive. It holds its profitability for future recovery operations and charity. The conceptual model can bring solutions pre and post crisis with its Islamic finance conversion branch/department. The conversion branch strengthens both the industry or the sector and the waqf itself. Also, the conversion branch provides additional benefits to the waqf's impact area with the blessings of an interest-free financial environment.

This study aims to propose and discuss the feasibility of the musharakah waqf model, which can be an important component of the solution to capitalist opportunism by conducting a critical analysis of the current crisis literature. The study analyzes the relation between capitalism and crisis in the first section from Islamic economics thought perspective. The second section analysis the applicability of the waqf model for different purposes. The last section indicates the potential of Islamic enterprise models as alternatives to capitalist enterprises by defining musharakah-waqf. It concludes with analysis provide valuable insight for future studies to be carried out on this field. Findings indicate that the proposed model can be an important part of solution against capitalist opportunism. The basis of the proposed model depends on Ahi (futuwwa) experience in Anatolia. The proposed model can be considered as a country level policy. 


\section{Giriş}

Kapitalizm bir arz teorisidir. Temel motivasyonu kıtlık sorununun aşılması için arzda büyümenin sürekliliğinin sağlanmasıdır. Büyüme, belirli tolerans sağlandıktan sonra "diğerinin" (kapitalizmde ikincil unsur kabul edilen geniş toplum kesimleri) aleyhine bir gelişim olarak tekelleşme stratejisidir. Daha ilk krizinden itibaren kapitalizm bu toleransı aşmış ve tekelleşmenin merkezine sermayeyi alarak yeniden örgütlenmiş bir iktisadi model olarak değerlendirilir (Foster \& McChesney 2012: 128).

Sonrasında kapitalizmin arz motivasyonunu yerini tüketime bırakmış, tüketim yönlü iktisat finansallaşmıș kapitalizmle birleșince, tüketim yönlü büyüme uğrunda ekonominin sürdürülebilirliğinde kilit rol oynayan bölüşüm gibi değerler göz ardı edilmiştir. Kapitalist ahlakın bu yok saymayı biçimlendirdiğini tespit etmek mümkündür (More, 2017). Bölüşümü örgütlemeyen kapitalizm, doğal sonuç olarak tüketim sorunu yaşamış ve sistem aksak doğasına uygun olarak krizli bir yapıya bürünmüştür. Keynes bu durumu konjonktür dalgası biçiminde teoriye aktarmıştır (Grossberg, 2010). Buna göre ekonomi inişler ve çıkışlar dönemlerinin birbirini takip ettiği bir gelişim izler.

Diğer taraftan sermayeyi faizle ilişkilendiren kapitalist model, yatırımın karlılığı piyasa faiz oranlarına eşit veya eksik seviyeye ulaştığında ilave krizler üretmiş̧tir. Finansallaşmanın beslediği bu mekanizma, kapitalizmin en önemli aracına dönüşmüştür. Anomali olan krizlerin kapitalizm içerisindeki sunumu böylece fırsat kavramı etrafında dayatılmıştır. Kaçınılmaz olarak fırsat arayışı cari iktisadi modelin temel önerisi haline gelmiştir (Schumpeter, 2006: 100).

Schumpeter, iktisadi modelin genel karakterini yaratıcı yıkım biçiminde tanımlanmaktadır (Schumpeter, 1942: 83). Doğal olarak firsatçılık modelin aktör tanımının temel özelliği olarak ele alınır hale gelmiștir (Williamson, 1993: 97). Neticede modelin sosyolojisi tam olarak fırsatçllık olgusu üzerine kurulmuştur (Bulut, 2015).

Dünyanın herhangi bir yerinde herhangi bir anda kriz içinde bulunan iktisadi aktörler bulmak mümkündür. Mevcut iktisadi yapı bir firsat olarak ortaya koyduğu bu kusurunu, firsatçllığı ve simsarlığı beslemek için kullanmaktadır. Firsatçı karakterlerin kapitalizm yarattığı sosyoloji içerisinde sayıları artmış ve sistemden kapitalistler ayıklanacağı yerde firsatçı olmayanlar elenmiştir. Böylece firsatçllar kapitalizmin asli aktörlerine dönüșmüştür. 
Kriz içerisindeki ekonomik aktörlerin varlıklarını piyasa değerinin altında satın almaya konsantre olmuş olan bu grup, istihdam, emek ve sürdürülebilirlik sorunları üretmektedir. Bu aktörlerin kendi karlılıkları uğruna istihdam, emek ve sürdürülebilirliği tükettiği de anlaşılabilir. Bu yolla ekonomiye yarar değil belki zarar üretmektedirler.

Rasyonel olmayan matematiksel ilişkileri açıklamaya çalışan ve farklı alanlara yönelen "arama teorisinin" (High, 1983: 263) yaklaşımına göre firsatçılığı kar odaklılık beslemektedir. Buna karşın arama teorisi yaklaşımı alternatif olarak "sürdürülebilirlik odaklılık" merkezli hedeflemeyi önermiştir. Bu yaklaşım karşılık bulsa da iktisadi model fırsatçılık dışındaki yaklaşımları irrasyonel olarak ele aldığından karlılığın sürdürülebilirliği noktasında karar bulmuştur.

İslam iktisadının kurumsal yapılarından birisi olan vakıf modeli tam da ifade edilmeye çalışıldığı gibi sürdürülebilirlik odaklı bir iş modeline sahiptir. Bu çalışmada kapitalist fırsatçılık karşısında güçlü bir alternatif getirebilecek yeni bir vakıf modeli önerilmektedir. Bu yapı muşaraka vakfı olarak sunulmuş ve öneriye olan ihtiyaç İslam iktisadı perspektifinden kriz literatüründeki tartışmaların sistematik analizi üzerine kurulmuştur.

Kriz yaşayan aktörlerin, varlıklarının fırsatçı simsarların eline geçmesi yerine sahip olduğu kaynaklar ve uzmanlığıyla ortaklık kuran muşaraka vakfı, sürdürülebilirlik anlamında güçlü bir çözüm önerisi sunmaktadır ve Ahi geleneği model kurgusu için yeterli ipucu vermektedir.

Çalışmanın ilk bölümünde kapitalizm ve kriz ilişkisi İslam iktisat literatürü çerçevesinde incelenmiştir. İkinci bölümde vakıf modeline ilişkin tartışmalar vakfın farklı alanlara uygulanabilecek karakterini ortaya koymak üzere analiz edilmiştir. Üçüncü bölümde muşaraka vakfı tanımlanarak iktisadi faydaları üzerinde durulmuştur. Önerilen vakfın iş modeli tarif edilerek uygulanabilirliği tartışılmıştır. Yöntem olarak sistematik literatür analizine başvurulmuş ve kurgu Ahi sandığı modelinden esinlenerek oluşturulmuştur. Bu çalışma İslam iktisat düşüncesinin şekillenmesi üzere yeni model geliştirmeye dönüktür. Bu alanda yapılacak çalışmalar ve düzenleyiciler açısından önemlidir.

\section{Kapitalizm ve Kriz İlişkisine Dair İslam İktisadı ve Finansı Literatürü}

Kapitalizmin bölüşüm sorununa çözüm üretmemesi devam eden talep krizlerini beslemektedir. Aslında ortada hiçbir zaman bir talep krizi olmamış bilakis bölüşüm krizleri talep krizi şeklinde kendisini göstermiştir denebilir. Cari olan bu iktisadi model geniş çaplı krizleri sistemin bir parçası olarak sunar. Bunun yanında ekonomik aktör bazlı krizler kapitalizmin fiktif etkisinden kaynaklı şekilde çok şiddetli olmasa da her zaman karşılaşılabilecek bir sorundur.

Kriz yahut olağandışı şiddetli kriz kapitalizm açısından bir sistematik problem olarak sindirilmiştir (Kotz, 2009). Bu sayede birçok kriz türü adeta ar- 
sızca tanımlanmış ve kapitalist model içinde içselleştirilmiştir. Kalitatif veya kantitatif birçok çalışma bu içselleştirmeyi ortaya koymuştur (Dumenil \& Levy, 2011; Tabb, 2012; Saad-Filho, 2011; Overbeek \& Apeldoorn 2012; Cahill, 2014).

Modelin kendi sorunları yanında çözüm ararken geliştirdiği yapılar da krizin besleyicisi konumuna gelmiştir. Bunlardan en önemlisi finansallaşmadır. Kapitalizmin temel dinamiğine dönüșen finansallaşma son dönemde krizlerde temel etken olarak rol almaktadır (Palley, 2010). Esasen dengeli kriz olağan bir durum olmakla beraber kapitalist finansallaşmanın fiktif yapısı krizi tıpkı bir kötü son şiddetinde olağanüstü yoğunlukla yaşatmaktadır.

Finansallaşmanın geliştirdiği kurumlar ve post-aktörler de haliyle krizlerde başrol almaktadır. Bunlar krizin kaynağı olan finansal kurumlar ve kriz sonrası ortaya çıkan alım "fırsatlarından" yararlanan fırsatçı simsarlar olarak ikiye ayrılabilir. Birinci grup iktisadi aktörlerin krizlerdeki rolü de araştırmalara konu edilmiştir (Riaz et al., 2011). Ancak ikinci grubun krizlerdeki rolü ile ilgili çalışma sınırlıdır. Aynı zamanda kriz sonrası davranışlarının etkisi incelenmemektedir.

Fırsatçıların birçok firmayı bilinçli olarak krize sürüklemesi ve varlıklarına sahip olmaya çalışması dahi bugün stratejik yönetim başlığında tartışılmaktadır (David, 2009). Esas olarak üçüncü tarafların bu ilişkiden zarar görmesi nedeniyle dünyanın farklı yerlerinde davalar açılarak suçluların cezalandırıldığı bilinmektedir. Fakat üçüncü taraflara dokunmayan simsarlıklar kapitalizm içerisinde kabul edilebilir. Daha doğrusu üçüncü tarafın kim olduğuna bağlı olarak bu ilişkinin şekillendiği düşünülebilir.

$\mathrm{Bu}$ problemler nedeniyle iktisadi yapıya alternatifler getirilmesinin yanında finansal aktörlerin sistem içerisindeki konumun da tartışıldığı birçok çalışma geliştirilmektedir. Özellikle kriz sonrası dönemlerde yoğunlaşan bu çalışmalar mevcut aktörler üzerine sürdürülebilirlik ve sosyal sorumluluk gibi değerlendirmelere sıkışmıştır. Kurumsal yapı alternatifleri ise bu anlamda ilgi çeken yaklaşımlar olarak görülmemektedir. Elbette mevcut iktisadi model içerisinde yapılan değerlendirmeler çözüm üretmekte kısırdır. Fakat İslam iktisadi düşüncesi içerisinde gerçekleştirilen çalışmalar bu konuda alternatifler sunmak gücüne sahiptir.

Krizleri İslam iktisat düşüncesi bakımından inceleyen çalışmasında Siddiqi (2009), ahlaki bozulmanın etkili olduğunu tartışmıştır. Çalışmada toplumların ve kurumların birbirine anlamlı desteğinin önemi üzerinde durmuştur. Somut bir kurumsal yapı önermeyen çalışma bu alanda getirilecek öneriler için teşvik edicidir. Önemli bir not olarak dayanışmanın krizler karşısında belirleyici olabileceği çalışma üzerinden yorumlanabilir.

Chapra (2011) son yaşanan küresel finans krizinde finansal disiplindeki bozulmanın etkili olduğu ve İslam ekonomisinin temel unsuru olan risk pay- 
laşımının krizlerle mücadelede etkili olabileceği üzerinde durmuştur. Çalışmada risk paylaşımının vakıf biçimlenmesi üzerinde durulmamıștır. Fakat muşaraka temelinde faaliyet göstermesi düşünülecek bir vakıf modelinin risk paylaşımı perspektifinden krizler karşısında etkin olabileceği belirleyici bir çlkarım olarak düşünülebilir.

Ahmad (2010) de krizlere maruz kalmamak için İslami finansın etkin olduğunu tartışmıştır. Çalışmanın bulguları kurumsal yapı önerisinin önemini göstermektedir. Fakat benzer konudaki farklı bir çalışmada İslami finans endüstrisinin, krizlerde kapitalist yapılarla aynı hataları yapabileceği de gösterilmiş olduğundan bu kurumların yönetiminin farkındalığının güçlü olmasında yarar görülmektedir (Smolo \& Mirakhor, 2010). Smolo ve Mirakhor'un ulaştığı değerlendirmede kapitalist perspektiften sürdürülebilirliği mümkün olmayan kar odaklılığın belirleyici olduğu düşünülebilir. İslami finansal kurumlar için "niyetin" kapitalizmin amaçlarından arındırılmasında ve sorumluluk duygusunun yönetimler için ön planda tutulmasında varoluşsal bir yön bulunur.

Bu değerlendirmeler yanında ortaklık temelli İslami finans modellerinin girişimcinin ve sosyo-ekonomik refahın belirleyicisi olarak krizler karşısında ele alınabileceğini gösteren çalışmalarıyla Hassan ve Kayed toplumsal refahı önceleyen bir model önerisini teşvik etmektedir (Hassan \& Kayed, 2009). Böylece kurumsal modelin önceliği belirlenebilir.

$\mathrm{Bu}$ anlamda akla gelebilecek olan en önemli İslam iktisat kurumlarından birisi olarak vakıf fikri ön plana çıkmaktadır. Halihazırda kapitalizmin aşırılık anlamındaki dinamiklerinden sakınmak için birçok liberal ekonomi dahi kooperatif modeli üzerine sektör oluşturmuştur. Bu durum vakıf modelinin etkin rolü için bir diğer önemli karine olarak kabul edilebilir.

Bu tartışmaların bir özeti olarak; incelenen literatürde krizler ve İslam ekonomisi ilişkisini ele alan çalışmalar, dayanışma, ortaklık, sosyal refah, kurumsal çözümler gibi başlıkları vurgulamakta veya ön plana çıkarmaktadır. Bu başlıkları birleştiren veya ortak kümeyi temsil eden en etkin kurumsal yapınınsa vakıf olduğunu tespit etmek gerekir.

\section{Vakıf Modeli}

Vakıf, Anadolu'daki anlatıya göre Hz. İbrahim'in (as) tanıttığı ve ilk vakıf mütevellisi olarak faaliyet gösterdiği kadim bir İslami sosyal hizmet örneğidir. Rivayete göre vakfettiği sürüleri genişletmiş ve insanların yararına sunmuştur. Sonra da Hz. Muhammed (sas) sahip olduğu birtakım varlıklarını vakfederek ümmete yol göstermiştir. Kuran (2011), vakfı, mülkiyetin iktisadi güvenliği için sunulan bir sosyal hizmet uygulaması ifade etmektedir. Kala (2019) bu kurguyu kurtarılmış kapital olarak nitelendirmektedir. Mülkiyetin iktisadi güvenliği veya kapitalin kurtarılması ifadeleri İslam medeniyetinde Allah için insanlık namına sunulan bir taahhüttür. 
Sonrasında vakıf medeniyeti özellikle Selçuklu ve Osmanlı tecrübeleri ile yaygınlaşmış ve vakıf kurumunu tek başına bir sosyal hizmet faaliyeti olarak açıklamak yetersiz kalmıştır. Vakfın sosyal hizmet özelliğinin yanı sıra müstakil bir iktisadi aktör niteliğinde olduğu da tespit edilmiștir (Babacan 2011). Özellikle Osmanlı tecrübesi vakfi, bir sektör olarak ele almıştır (Genç, 2018). Asutay'ın (2007) aynı konudaki görüşleri de Genç'in yaklaşımına paraleldir. Aynı zamanda vakıf modelinin ekonomik başarısızlıklar karşısında üçüncü bir sektör olarak ele alınmasının önemini vurgulamıştır.

Toplumsal refahın vakıf ile öncelenmesinin mümkün olduğunu gösteren yaklaşımlar da literatürdeki tespitleri güçlendirmektedir (Zuki, 2012). Bu tür çalışmalar vakıf modelinin farklı sosyal modelleri tartmak için uygun bir zemin sunduğunu gösterir niteliktedir. Örneğin Salarzehi ve diğerleri (2010) vakıf modelinin sosyal girişimciliğin bir aracı olarak ele alınabileceğini tartışmıştır. $\mathrm{Bu}$ alanda bir ihtiyaç ve eksiklik olduğu ise açıktır.

Piyasa sistemi, girişimcileri sermaye tekelinin ve kapitalist firsatçılı̆̆ın karşısında yalnız bırakmaktadır. Kriz halinin gerçekleşmesi karşısında girişimcilerin bir sığınağı bulunmamaktadır. Bu nedenle uzun emeklerle ortaya çıkarılan değerler ve sürdürülebilirliğin kaynağı olan istihdam gibi kazanımlar kaybedilmektedir.

Girişimciyi güçlendirecek vakıf modelleri problemin çözümünde önemli bir rol oynayabilir. Çizakça (1998) vakıflar ve İslam ekonomisi konulu çalışmasinda mudaraba (emek-sermaye ortaklığı) modelinin önemi üzerinde durmuştur. Böylece girişimciyi güçlendiren bir vakıf modeli ortaya çıkarılabileceği anlaşılmaktadır.

Bugün vakıf modeli genellikle mikrofinans başlığı altında ele alınsa da klasik vakıflar altyapı yatırımlarına kadar çeşitli alanlarda hizmet vermekteydi. Örneğin Ahmed çalışmasında zekât, karz-ı hasen, vakıf gibi İslami finansal kurumları mikrofinans uygulamasının araçları olarak ele almışlardır (2002). Obaidullah gene mikrofinans alanında zekât, icara, vakıf, sadaka, istisna, istijrar, selem gibi birçok finansman yönteminin bir arada yer aldığı bir kâr amaçlı model de geliștirmiștir (2008). Benzer şekilde Abdulrahaman ve Dean (2013) mikrofinans ile ilgili çalışmalarında sosyal sermaye kavramını ön plana çıarmıştır. İslami mikro finans alanında vakıf, sadaka, zekât ve karz-ı hasen gibi modelleri bu bağlamda ele almışlardır. Vekalet-vakıf modeli ile zekâtı birleștiren bir kompozit model önerisi de geliştirmişlerdir.

Vakıf modelinin son dönemde mikrofinans alanına sıkıştırılarak tartışılması bir çeşitlilik sunması yanında bir tür eksiklik olarak değerlendirilebilir. Dahası mikrofinans konsepti en başında ifade biçimiyle kapitalisttir. Bu konuda Lütfi Bergen'in çeşitli platformlarda serz ettikleri görüşleri yerindedir. Çünkü kapitalizm mikrofinansla finansal hizmet tüketimi bakımından toplumu yahut ekonominin aktörlerini avantajlılar/dezavantajlılar biçiminde bir sınıf ayrımına tabi tutar. Pek tabi bu servisin ifadesi ve uygulaması İslami mikro- 
finans olarak değil ancak "İslami sosyal finans" olarak ifade edildiği ve anlaşıldığı durumda doğrudur. İslami mikrofinans başlığındaki tartışmaları, tam da Smolo ve Mirakhor tarafından bahsedildiği biçimde İslami finansın yanlış yönetiminin mükemmel bir eğilimi olarak görmekle beraber vakıf modelinin çeşitli alanlara uygulanabilmek üzere elverişli bir yapı sunduğunu göstermeleri bakımından faydalı bulabileceğimi söyleyebilirim.

Vakıf konusu etrafındaki diğer çalışmaların önereceğimiz model kurgusunu besleyecek tespitleri olduğunu da ortaya koymak gerekir. Örneğin Hasan ve Abdullah (2008) vakıfların kendi yatırımlarının kalkınmayla ilişkisini ve uygulanabilirliğini göstermiștir. Vakıf modelinin tarihi gelişimini inceleyen model çalışmasında Kato (2004), endüstri odaklı bir model yerine toplum odaklı perspektif geliştirerek vakıf sistemini ele alırken yaklaşımını önemli İslam düşünürlerinin görüșleriyle desteklemiștir. Tartışmalar, sürdürülebilir endüstri ve kalkınmadan her ikisini birden hedef alarak da vakıf modelinin başarısını pekiştirebileceğini serz etmektedir şeklinde yorumlanabilir.

Vakıf modelinin hem üretimi hem de sosyali önceleyen bu yönüne rağmen etkinliğini görece kaybetmiş olması ise modeli bir çözüm önerisi olarak sunmak anlamında ayrı bir tartışma konusu oluşturur. Cevap Kuran'a göre paradigma değişiminde yatmaktadır ve bu yöndeki diğer çalışmaların kanaati benzerdir. Schoenblum (1999) çalışmasında hukuki düzenlemelerin vakıfların düşüşüne ve "trust"ların yükselişine neden olduğunu güçlü argümanlarla ortaya koymaktadır. Bu ilişkinin vakıf modelinin endüstri dışına itilmesinde ve tartışmaların "sempati" oluşturma adına ve kapitalizmin sırtını kaşır nitelikte mikrofinans gibi dar alanlara sıkıştırılmasında etkisi olduğu düşünülebilir. Yani bir nebze varlık zeminini kapitalist dünya görüşü içerisinde kaybettiği düşünülen yapıya yeniden rol biçme gayretleri, kapitalizmin hoşuna gidecek şekilde sunulmaktadır. Bilakis kapitalizmin değil insanlığın amaçlarına hizmet etmek üzere vakıf modelini ihya etmeyi ve hatta vakıf modelini endüstri-toplum şeklinde daraltmamak gerektiğini de tespit etmek gerekir. Mevcut düzenleme zemininde dahi vakıflar asıl misyonlarını yerine getirebilirler. Üstelik hem fertlerin hem firmaların dönemsel olarak vakıf hizmetlerine ihtiyaç duyabileceği açık olmakla beraber vakıf kültürünün paradigmaya rağmen toplum içerisinde canlı olduğuna birçok delil vardır. Vakıfla ilgili tartışmaların nitelik ve niceliksel yönü ve vakıf benzeri yapıların batı ekonomilerinde ${ }^{2}$ yaygınlaşmalarının nedenleri arasında bu deliller bulunabilir.

Tarihi tecrübenin önemli bir bileșeni olarak vakıfların farklı kullanım amaçları da incelenmiştir. İlgili birçok çalışmada (Lahsasna, 2010; Chowdury, Ghazali \& Ibrahim, 2011; Mohsin, 2013; Ibrahim, Amir \& Masron, 2013; Bulut \& Korkut, 2016) para vakıfları üzerinde durulmuştur. Bu vakıflar bir tür finans

2 Önerilen kurumsal yapının bir kümelenme modeli olarak da ele alınabileceği düşünüldüğünde, çıkaran yapısının daha dikkatle yeniden düşünülmesi de gerekmektedir. 
kurumu olarak faaliyet göstermiştir. Uygulama alanları içerisinde ortaklık modellerine de yer vermişlerdir. Bugün var olmuyor olmaları belki bu çalışmada üzerinde çokça durulan yanlış yönetim sonucu olarak görülebilir. Hatta modern bankacilığın bu kurumlar karşısına bir kurtarıcı niteliğinde sunulması düşündürücüdür (Bkz. Resim 1). Buna rağmen finansal aracılığın kar odaklı bir faaliyet türü olamayacağını ifade eden en önemli tecrübeler arasına bugünün katılım finansı yanında para vakıflarını almak gerekir.

Resim 1. Cumhuriyet Döneminde Bankacılığın Karikatürle Sunumu

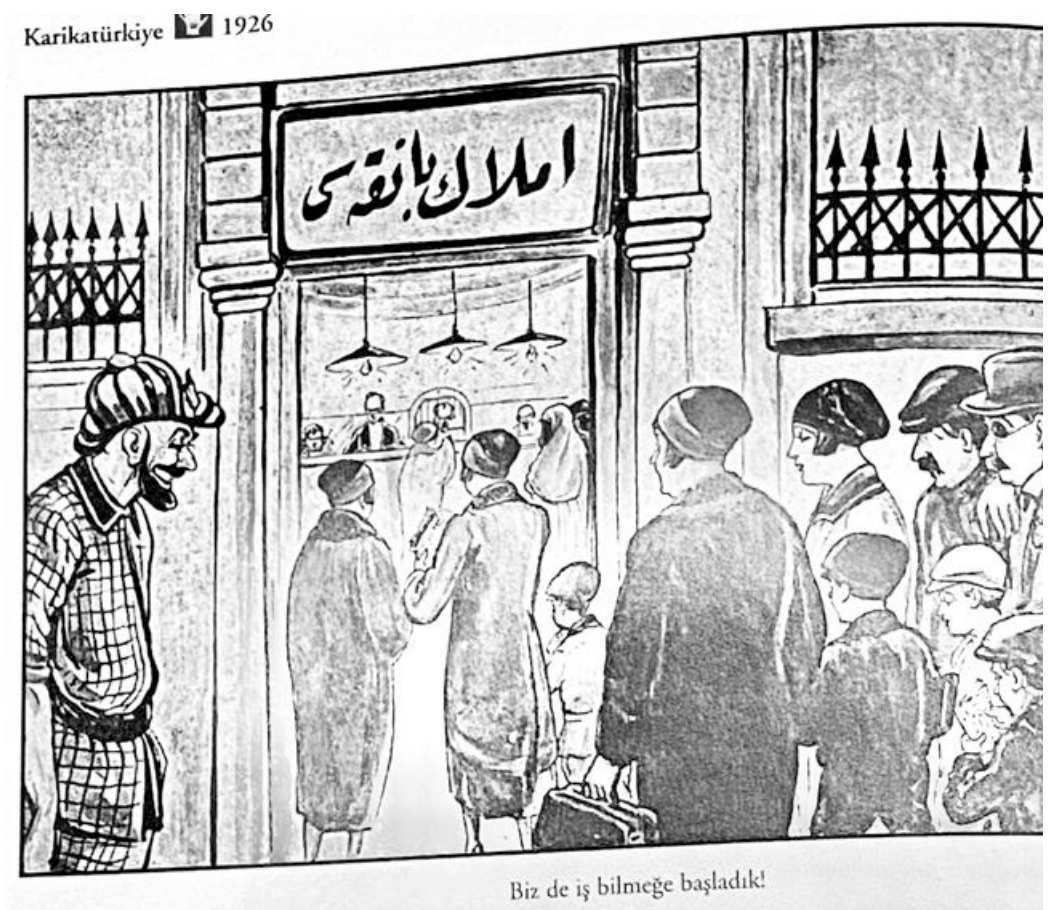

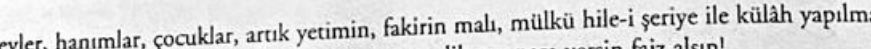
(çoğalulacak! Isteyen para alsın, iş yapsın, dileyen para versin faiz alsın!

\section{Kaynak: KarikaTürkiye 1923-2008 1.Cilt}

Vakıfla ilgili bunlar dışındaki çalışmaların geneli bir bakıma paradigmayı da kanıksamış yahut yenik düşmüş biçimde sektör özelliği göz ardı edilerek daha çok büyüme değil kalkınma odaklıdır. Bu durum her halükârda vakıf modelinin üstünlügünü gösterir nitelikte kapitalizmin bir diğer sorun alanı olan kalkınma problemine İslam ekonomisinin çözümler sunduğunu ve çoklu fayda elde etmenin mümkün olduğunu göstermektedir. 
Vakıf modelinin mevcut düzenleme zemininde dahi hem büyüme hem kalkınma yönü olabileceğini belirtmek gerekir. Buradan anlaşılacağı üzere İslam iktisat düşüncesinin kurumları salt büyüme odaklı olmayıp "sorumluluk" sahibi yapılar olduğundan sürdürülebilir bir iktisadi sistemi besleyeceği anlaşılabilir. Bunun karşısında kapitalizmin zehirli bal çalan fiktifliği kuru bir dala benzer.

Bir iktisadi modele gücünü veren kurumlarıdır. İslam iktisat düşüncesi de gücünü kurumlarından almaktadır. Bu bakımdan kapitalizm karşısında geliştirilmeye çalıșılan iktisadi modellerin hepsi bir yana İslam iktisat düşüncesi avantajlı konumdadır. Belki bir kader olarak kapitalizmin bu tecrübesinin İslam iktisat düşüncesinin anlaşılabilmesi için bir gereklilik olarak karşımıza çıktığının da not edilmesi düşünülebilir. Yani vakıf gibi İslam iktisat düşüncesinden beslenen kurumların kapitalizmin sorunlu yapısı iyice gün yüzüne çıkmış olduğundan getireceği çözümlerin ele alınması sürecin doğal sonucu olarak görülebilir. Kapitalizm, asli unsurlarının menfaat edinemediği hallerde "diğerlerinden" esirgeme (paylaşmama) üzerine kurulu bir modeldir. Hatta kendi krizlerinin maliyetini dayanışarak değil diğerlerine ödeterek aşmaktadır. Alternatif ihtiyacının merkezine bu sorunu almak ve toplumsal sorumluluk etrafında kurumsal yapıları ele almak gerekir.

İslam iktisat düşüncesinin merkezindeki dayanışma modellerinin her sorunda çözüm olarak dile getirilmesinin ve ön plana çlkarılmasının nedeni de buna işaret etmektedir. Asıl itibariyle kalkınmayı da besleyen dayanışma modelleri refahı toplum tabanına yaymaktadır. Kapitalizmin tekelciliği karşısında getirdiği bu imkân İslam iktisat düşüncesi ve kurumlarını önümüzdeki dönemde daha güçlü biçimde gündeme taşıyacaktır.

Schumpeter'e (1942) göre artan tekelleşme kapitalizmin sonunu getirecektir. Kapitalist tekelleşmeyle ortaya çıkan durum karşısında İslam iktisat düşüncesi ve kurumlarının sunduğu çözümler ve pratik uygulamanın sonuçları yeterli biçimde incelenebilirse yön arayışı için önemli bir farkındalık olacağı düşünülebilir. Artan kapitalist tekelleşmenin İslam iktisat düşüncesi ve kurumlarına dönük farkındalığı güçlendireceğini beklemek olağandır. İslam iktisat düşüncesinin önümüzdeki dönemde ön plana çıkması ve dahi sürdürülebilirliği mevcut iktisadi modelin sorunları gün yüzüne çıktıkça kaçınılmaz olacaktır. Bu bakımdan kapitalizmin fırsatçılık sorununa muşaraka vakfı önerisi farkındalığı güçlendirecek önemli bir çözüm olarak ele alınabilir. Vakıf modeli etrafındaki yaklaşımların bu yönü genel olarak Bulut ve Korkut (2019) tarafından da ortaya konmuştur.

\section{Muşaraka Vakfı}

Muşaraka vakfı bireysel, sektörel veya bölgesel krizlerin çözüm merkezi olan kriz içindeki iktisadi aktörlerin fırsatçılardan korunmasını sağlayacak bir tür 
kayyumluk müessesesidir. Esas olarak burada bahsedilen model yeni olmamakla beraber yeniden ortaya konmaya çalışılmaktadır.

İktisadi tecrübemiz Ahilik geleneği ve esnaflık kültürü içerisinde bu tür güvenlik mekanizmalarını barındırır. Fakat bu yapıların kurumsallaşması politika seviyesinde gerçekleşmemiş veya kapitalizmin kıyıcllığı karşısında hakkınca korunamayarak sürdürülememiştir. Bu çalışmadaki gayret müstakil olarak modelin tanımlanması, kurumsal yapının süreç ve kodlarının kurulması ve böylece sürdürülebilir biçimde özde var olanın yeniden ihyasıdır.

\section{Ahilik Sistemi ve Muşaraka Vakfina Duyulan İhtiyaç}

Ahilik mekanizması uzman yetiştiren sonrasında yetiștirdiği uzmanların üretime katılması için finansman sağlayan bir mekanizmadır. Konumuzla asıl alakalı olan husus teşkilat içerisinde ekonomik başarısızlık yaşayanlara kaynak sağlamak konusunda kurumsallaşmış bir sandık bulunmasıdır. Bu sandık öyle bir yapıdadır ki bütçesinden, kriz içindeki teşkilat üyelerine faaliyetlerini sürdürmesi için kaynak aktarılabilmektedir (Kala, 2019).

Keza esnaflık kültürü kriz yaşayan sektör üyelerine, komşularına ve ilişkide oldukları çıkar gruplarına destek olunmasını sağlayan kodlar barındırır. Esnaflık kültürü içerisinde kurumsallaşamamış olan bu dayanışma mekanizmasının kapitalistleșen kültür ve modernizm etkisi altında izleri yok olmak üzeredir. Buna rağmen kadim gelenekle yetişen esnaf arasındaki iş kültürü içerisinde dayanışma ahlakı hala güçlüdür.

Kökeni Abbasiler'deki Fütüvvet kurumuna dayandırılan Ahilikte mesleki dayanışma esas kabul edilir. Yapı içinde kurumsallaşma da ihmal edilmemiştir. Örneğin üyeler ve çevre için dahi bir sosyal güvenlik kurumu olarak Orta Sandığı Ahi teşkilatlarına bağlı ayrı bir şube olarak faaliyet göstermiştir. Orta Sandığında iki hesap krediler ve yardımlar şeklinde işletilmiștir. İlginç bir detay Ramazan aylarında sandık hesabına hatim indirilip çevreye pilav sunulmasıdır. Cenaze giderlerinden, fakirlere yardıma ve işleri bozulan esnafların kaynak ihtiyaçlarının karşılanmasına kadar geniş bir yelpazede Orta Sandığı hem sosyal hem de bir tür sigorta fonu olarak kullanılmıștır. Orta Sandığı gelir kalemleri belirlenmiş ve denetlenen bir yapıdır (Günay, 2008). Üyelerin kriz yaşaması halinde Teşkilat, Sandık aracılığıyla kayyum olarak davranmaktadır. Özellikle dönemi içerisinde genellikle şahıs işletmesi olan üyelerin sürdürülebilirliğini etkileyen en önemli durum vefat halidir. Örneğin bir üye vefat ettiğinde ticari faaliyetine kimin devam edeceğine mirasçlları ve iş çevresi yararına bağlı olduğu Ahi birliği karar vermektedir. ${ }^{3}$

3 Urhan Amca ismiyle meşhur kısa film ki çeşitli video paylaşım platformlarında bulunabilir; Urhan amcanın semercilik faaliyetinin ot sağlayan tedarikçiden alıcısı olan perakendecilere kadar ki zincirde oluşturduğu hacmi ve manayı ifadesinin buradaki tartışmaya anlam katması bakımından okuyucuya tekraren izlemesi tavsiye olunur. 
Bugün hala yerleşik çarşılarda bu tür dayanışma mekanizmaları kültürün bir parçasıdır. Fakat Ahilik sistemi çözülmüş ve kurumsal yapısı ortadan kalkmıştır. Sistemin dayanışma mekanizmasına duyulan ihtiyaç ise kapitalizmin kar odaklı spekülatif yaklaşımının büyüttüğü fırsatçılık nedeniyle artmıştır (Kara, 2009).

Ahi birliklerinin kayyum gibi davranabilme kabiliyeti sahip oldukları uzmanlık sayesindedir. Birlik yönetimi üyelerden oluşturulur ve üyeler benzer meslek kollarında uzmanlıkları ya da diğer ifadeyle bilgi-birikimleri (know-how) genel kabul görenlerden seçilir. Bu sayede kriz içerisindeki üyenin durumunu analiz ederek sorunlarına doğru çözümleri sunabilecek kabiliyete sahiptirler. Sürdürülebilirlik anlamında bilgi birikim önemlidir. Keynes de sürdürülebilirlik için bilginin önemini üzerinde durmuştur (O’Dennell, 1990: 340) ve kapitalizme eleştiriler getirmiştir (Kar, 2017; Boz, 2018).

Ahi kültürünün bütününe ve bileşenlerine duyulan ihtiyaç hükümetler seviyesinde de görülmektedir. Birçok ekonomi bu türden yapıların cüzlerinden olan finansal teşvik, hibe, teminat gibi destekler sağlayacak mekanizmalar geliştirmiştir. Fakat bütüncül bir yaklaşım getirilememiştir. Muşaraka vakfı ihtiyacın yekününü ifade eden bütüncül bir çözüm önerisi olarak ele alınabilir.

\section{Muşaraka Vakıf Modeli ve İlkeleri}

Kapitalist fırsatçılık ve şirket simsarlığı karşısında vakıf temelli model kurgularının kurumsal alternatif olarak getirilebileceğinin böylece yeni olmadığı açıktır. Bahse konu muşaraka vakfı modeli önerisi dayanışma ilkesiyle ticari faaliyetini sürdürmekte zorlanan işletmelere muşarik olarak katma değer sağlamak üzere örgütlenmiş ve potansiyel kullanıcılarının kendi öz varlığı olan bir yapıdadır. Model önerisi ortaklığa katılan bir tür sivil kayyum olarak da düşünülebilir. Anlaşılacağı üzere varlığının çoklu fayda sağlaması muhtemel olmakla beraber asıl çıkış felsefesi kapitalizmin simsar şirketlerinin/ aktörlerinin antitezini oluşturmaktır. Model sektörel veya bölgesel konsantrasyonlu sınırlı muşaraka vakfı şeklinde tanımlanabileceği gibi sınırsız muşaraka vakfı biçiminde de kurgulanabilir.

Muşaraka vakfı bir diğer ifade ile daha önce bahsedilen "kurtarılmış kapital” çözümüdür. Temel çözüm alanı olan kapitalist firsatçılık, Attar'ın (2012) Pendname'sinden esinle alçakça menfaat beklentisi olarak tanımlanabilir. Öneri model muşaraka üzerine kurgulanmıştır. Bu yönüyle literatürde vakıf başlığındaki çalışmalarda referans edilen İslami finans yöntemlerinden farklı olması hasebiyle özgündür ki modelin muşaraka üzerine kurgulanması bir gereklilik olarak ele alınmaktadır. Bu model ile vakıf ortaklar edinmekte ya da bir diğer ifadeyle ortaklıklara katılmaktadır. Fakat kurulması beklenen bu ortaklıklar bütünü daha çok faaliyetini tekamüle ulaştırmak için bir tür varlık fonu niteliği taşımaktadır. Model kendi içerisinde bir vakıf olmasının yanında çevresine dönük faaliyeti muşaraka yöntemi üzerine kurgulandığından adlandırma muşaraka vakfı şeklinde yapılmıştır. Vakıf mütevellisi Ahi Evran Vakıfları gibi iş dünyasının veya sınırlı muşaraka ise sektörünün yetkinlerinden 
oluşturulur. Kurum daha önce tespit edildiği üzere sivil kayyum olarak hizmet üretecektir ve idaresinin emin eller niteliğindeki uzmanlığa sahip olması gerekir. Tarihi tecrübe bir güvence mekanizması (Gürsoy, 2014) da sunduğundan modelin tekafül karakterli olduğu söylenebilir.

Yönetim yani mütevelli bu yönüyle vakfın asli unsurudur. Tamamlayıcı olaraksa muşaraka vakfına ilişkin model ve ilke önerileri belirleyicidir. Bunların ortaya konulması modelin ișlerliğine delil olușturacak niteliktedir. Muhtemel bir muşaraka vakfı modeli Şekil 1'de gösterilmiştir. Buna göre belirli bir grup, sektör veya bölge muşaraka vakfını kurarak ilk sermayesini oluşturacak kaynağı aktarırlar. Bu kaynak vakfın kurtarma operasyonlarının gerçekleștirilmesi üzere fon sağlamak niteliğindedir. Böylece vakfın birincil gelir kalemi üyelik katkılarından oluşur. Üyelik, oda faaliyetlerinde olduğu gibi yasal bir gereklilik olarak da ele alınabilir. Vakfın diğer gelir imkanları ise vakıf çalışmalarının süreç adımları tarif edilirken ifade edilecektir.

Buna göre vakıf, karar süreçlerinde yedi önemli adımı göz önünde bulundurur:

- $\quad$ Bunlardan birincisi vakfa başvuranın faaliyetinin fikhi yönden meşruluğunun (vakıf prensiplerine uygunluğunun) tespitidir.

- $\quad$ Faaliyetin vakıf prensiplerine uygunluğunun müspet olarak tespiti halinde sonraki aşama başvurunun beklenen pay satış tutarının vakfın kurtarma bütçesi içerisinde olup olmadığının incelenmesidir. Vakıf kurtarma bütçesinin hacim maksimlerini ve pay tutar sınırlarını kabul edilecek kurtarma politikası içerisinde veya kuruluş sözleşmesinde tespit edebilir.

- $\quad$ Üçüncü olarak başvuranın durumu belirleyicidir. Başvuran mevcut durumunu şeffaf biçimde başvuru sırasında raporlayarak beyan eder. Vakfin uzmanları bu rapora ve kendi incelemelerine dayanarak bir değerlendirmede bulunur. Bu değerlendirme kurtarma bütçesinin temelini oluşturur. Vakıf bağımsız denetçilerden temin edilecek raporlar üzerine incelemesini gerçekleştirmeyi de ilke edinebilir.

- Dördüncü olarak sınırlı muşaraka modelindeki vakıf için başvuranın başarısızlığı halinde sektörün kalanına yapacağı etkinin büyüklüğü değerlendirilir. Sınırlı muşaraka öngörülmemişse iktisadi çevreye etkisi (İktisadi Çevre Etki Raporu) dikkate alınır.

- Beşinci olarak başvuranın, başvuru esnasında paylarının veya varlıklarının vakfedeceği kısmına ilişkin taahhüt miktarları değerlendirilir. Model içerisinde vakıf bir miktar pay alımı gerçekleștirmekte ve bir kısım payın başvuran tarafindan bedelsiz devri beklenmektedir. Bedelsiz pay devri miktarı kabul edilecek kurtarma politikası içerisinde beyan edilebilir. Vakfin gelir kaleminin ikinci bileșeni bu şekilde bedelsiz aldı̆̆ı paylardır.

- $\quad$ Altıncı adım gerçekleştirilecek risk ortaklığı neticesinde oluşacak kara/zarara katılım oranın tayinidir. Kurtarma misyonunun başarısı ile oluşması umulan karlılık vakfin gelirlerinin üçüncü bileșenini oluşturmaktadır. 
- Yedinci adım vakfın çıkış stratejisini belirlemesidir. Muşaraka vakfı ile kurulacak ortaklık ilişkilerinde karşı taraflara hiçbir imtiyaz sağlanamaz. İşletme esas sözleşmesinde daha önce öngörülen tüm imtiyazların terki esastır. Çıkış stratejisi ortağa verilecek şufa hakkını tek imtiyaz olarak korur. Bu son adım vakfın gelir kalemlerinin sonuncu bileșenini de olușturur.

Çıkış stratejisi vakfın varoluş amacının en önemli besleyicisidir. Vakfın bilgi-birikimi ve sınırlı fiziki kaynakları ile zor durumdaki bir iktisadi aktörü ilave katma değerlerle yeni bir piyasa ortamına ve değerine taşıması böylece de kaynak yaratarak yeni kurtarmalar gerçekleștirmesi umulmaktadır. Çıkış stratejisinin başarıyla uygulanması aynı zamanda vakfın ilgili ekonomik birimle faaliyetini başarıya kavuşturduğu anlamına gelirken kendisine olan güvenin asıl gerekçesini oluşturacaktır.

Başvuru yapanlar kapitalist fırsatçılık karşısında tüm varlıklarını kaybedeceklerini bilirler. Bu ilişki vakıf gelirlerinin ikinci bileşeninin gerekçesini oluşturur. Buna göre başvuru sahipleri kabul cevabı almaları halinde pay ve varlıklarının bir bölümünü vakfetmeyi kabul ederler.

Başvuranın vakfın teklifini kabul etmesi halinde vakıf kontrolü devralır. Mevcut ortaklar uzmanlıklarına göre istihdam edilebilir. Yeterli uzmanlıklarının bulunmaması halinde yönetim ve operasyonlar anlamında sistem dışına çıkarılabilirler. Mevcut ortaklar muşaraka sözleşmesinde belirlenen nispette karlılık yaratılması mümkün olursa kardan pay alarak geçimlerini idame ettirirler.

Şekil 2. Muşaraka Vakfı Model Önerisi

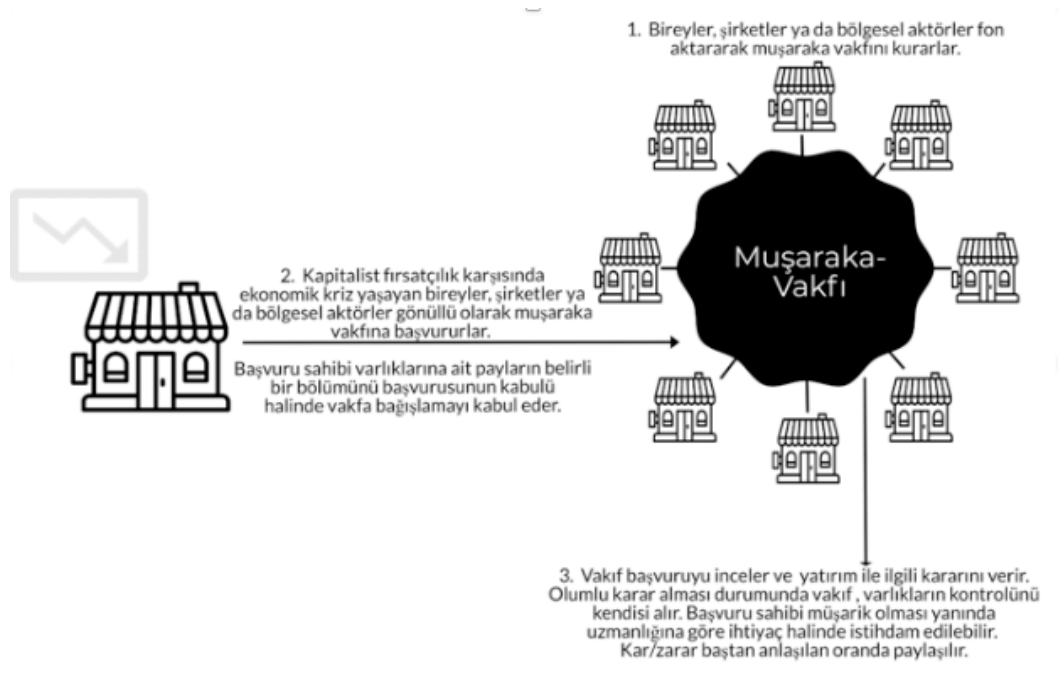

Vakıf elde ettiği kaynağı "kaynağa saygı” amacıyla âtıl kalması halinde portföy yöneticisi olarak katılım finans ilkeleri çerçevesinde değerlendirir. Muhtemel başvuralar için kaynak yapısını güçlendirir. Vakfın sınırlı veya sınırsız 
muşaraka modeli biçiminde kurulması kararının en başta verilmesi ve vakıf sözleşmesinde belirtilmesi beklenir. Sınırlı muşraka vakfı belli bir sektöre odaklanarak başvuru tabanını daraltır. Sınırlı muşaraka vakfı geliştirilmesi halinde bölgesel veya sektörel krizler karşısında odaklanılarak uzmanlık güçlendirilebilir. Sınırsız muşaraka vakfı ise sektör sınırlaması olmaksızın başvuru kabul etmeye hazırdır.

Muşaraka vakfı çeşitli yönetim fonksiyonları nedeniyle kriz yaşayan fakat sürdürülebilirliği bulunan firmalara başvuru esasıyla katma değer sağlayacak bir muşarik olarak katılmak üzere önerilmektedir. Diğer İslami finans yöntemleri dışında bu modelin güvenliğinin daha güçlü olduğu düşünülebilir. Bu tür bir vakfın amacı dışında kullanıma ve manipüle edilmeye çalışılacağı akla gelebilecektir. Hatta mudaraba, azalan muşaraka şeklinde türlerinin kriz yönetimi ve sürdürülebilirlik anlamında çok elverişli olmakla beraber amaç dışı kullanıma daha geniş zemin sağlaması ihtimaldir. Tarafların sorumluluklarının devam edeceği bir model olan muşaraka bu bakımdan mütevellinin elini güçlendirmektedir.

Vakıf yönetimi, kontrolünü aldığı işletmelerin ihtiyacı olan yönetim, inovasyon ve finans gibi alanlarda uzmanlar istihdam eder. Böylece işletmenin ortaya çıkarılması ve faaliyetinin gerçekleştirildiği altyapının kurulmasına verilen emek zayi edilmemiş dahası sosyo-ekonomik açıdan stratejik önem arz eden işgücü istihdamı kaybedilmemiş olur. Bunun yanında işletmenin başarısızlığından olumsuz etkilenebilecek ilişkili işletmelere güvence sağlanır. Böylece iktisadi ekosistemin sürdürülebilirliği güvence altına alınır. Ulaşılacak karlılıksa ileri kurtarma operasyonları ve hayır işleri için vakfın kendi sürdürülebilirliğini sağlar. Krizlerin neden olabileceği yıkımları önlemek üzere bu vakıf türünün sistemde aktör olarak yerini alması sağlanarak son dönemde görüldüğü gibi birçok krizde etkinlik sağlayabilir.4

Tüm bunlar yanında esas olarak vakfın başvuru çokluğunu önleyici hizmetler üretmesi beklenir. Bunun için bölgesinde veya sektöründeki ekonomik aktörlerin kurtarmaya gerek kalmayacak biçimde sürdürülebilirliklerini sağlayacak eğitim, danışmanlık gibi sosyo-ekonomik destekleri sağlaması beklenir. Hatta ekonomi geneline yayılacak vakıflaşma politikası üretilmesi halinde performans ölçüm kriterlerinin en önemlisi başvuru ihtiyacı azlığı olacak şekilde belirlenebilir.

Böylece sosyo-ekonomik destek fonksiyonları vakfın asıl faaliyetinin ilk bölümü olarak ele alınabilir. Asıl faaliyetin ikinci bölümü ise önlenemeyen kriz durumlarında başvuruları değerlendirerek kabul-red kararı vermesi ve kabul kararı halinde kurtarma operasyonu gerçekleștirmesidir.

4 Doğa Koleji markasıyla bilinen özel eğitim kurumunun İTÜ Vakfına devri bu bakımdan anlamlıdır. 
Vakfın faaliyetinin bir diğer bölümü devraldığı iktisadi aktörün uluslararası İslami standartlar etrafında bilanço yapısını faizsizleştirmeyi bütçelemesi ve iş süreçlerinin faizsizlik ilkelerine uyumunu artırmak üzere yeniden tanımlamasıdır.

$\mathrm{Bu}$ değerlendirmelerden anlaşlacağı üzere "kurtarma" hem operasyonel hem faizsizlik manası taşır. Vakıf bu hizmeti danıșmanlık faaliyeti kapsamında kontrolünde olmayan işletmeler için de sunabilir. Zira firma başarısızlıklarında toksik kapitalist finansallaşma etkendir. Bunun önüne geçmek üzere iktisadi aktörlerin faizsizleștirilmesi vakfın başarısının belirleyicilerindendir. Buna dönük olarak vakıf bir dönüşüm şubesi kurar. Vakfın faaliyetinin son bölümü ise gerçekleştireceği hayır işleridir.

\section{Faizsiz Dönüşüm Şubesi}

Krizlerin finansallaşmayla ilgisinden yukarıda bahsedilmiştir. Finansallaşma iktisadi sistemin bütününü toksikleştiren ve kriz üreten dinamiklerden birincisidir. Üstelik finansal kapitalizm, kapitalizmi sömürmektedir. Sektöründe veya bölgesindeki iktisadi aktörlerin kapitalist finans sistemiyle ilişkisini sonlandırmayı ve faizsizlik ilkesi etrafında bilançolarını yeniden örgütlemeyi yönetebilecek bir yapıya ihtiyaç vardır.

Bu türden bir dönüşüm salt faiz sorunuyla sınırlandırılmaz. İktisadi aktörün tüm akit tiplerinin ve iş süreçlerinin de yeniden ele alınarak faizsizlik ilkeleri etrafında değerlendirilmesi ve değişiklik ihtiyaçları için uygulanması gereklidir.

Faizsiz Dönüşüm Şubesi sektörde veya bölgede en iyi uygulamaların hâkim kılınması rolünü de üstlenmiş olacaktır. Böylece önerilen vakıf, faaliyeti sonucu uluslararası faizsiz finansal kuruluşların ve faizsiz fonların bölgeye veya sektöre cezbedilmesinde etkin rol oynayacaktır. Dönüşüm şubesinin ulusal ve uluslararası faizsiz finansal kurum, örgüt ve kuruluşlar ile de işbirliği sağlanabilecektir.

İleri aşamalarda bölgede veya sektörde yatırım yapmak isteyenlerin kendilerini Vakfın denetimine açacakları ve bu sayede faizsiz finans ortamının nimetlerinden faydalanacakları bir cazibe merkezi oluşturulması düşünülebilir. Ayrıca muşaraka vakfı üyeliği temel kredibilite göstergesi olacak etki ortaya çlkarabilir.

\section{Sonuç}

Kapitalizm fiktif krizler üreten bir yapıdır. Ekonomik aktörlerin herhangi bir zamanda ve herhangi bir yerde yıkıcı krizler yaşaması olağan kabul edilir. Bu sorun kapitalizm tarafindan firsat olarak sunulmaktadır. Bu durum sürdürülebilirlik, istihdam gibi alanlarda sorunlar yaratır. İş dünyasının tarihteki çeşitli uygulamalarının yeniden gündeme gelmesi bu alanda kapitalist fırsat- 
çllığa bir çözüm olarak sunulabilir. Vakıf ve Ahilik tecrübesi bu bakımdan belirleyicidir.

Vakıf modeli çeşitli alanlardaki uygulanabilirliğiyle kapitalizm kaynaklı sorunlara çözüm ihtiyacının bir bölümünü oluşturabilir. Bu çalışmada muşaraka vakfı olarak tanımlanan kurumsal yapı makro, sektörel ve bölgesel krizlerin çözüm modeli olarak tartışılmıştır. Modelin kurgusu Anadolu ticaret devriminin ana unsuru olan Ahilik tecrübesinden esinlenerek sunulmuştur.

İş modeli, gelir kaynakları, süreç adımları ve kurumsal yapısı tanımlanan muşaraka vakfı öncelikle başarısızlıkların önüne geçmek, sonrasında kriz yaşayan kurumların sürdürülebilirliğini ve mevcut istihdamın korunmasını sağlayabilecek özelliktedir. Muşaraka vakfı önerisi esas itibariyle dayanışma temelli bir sivil kayyum müessesedir. Aynı zamanda faizsiz dönüşüm hizmetiyle muşaraka vakfı etrafında bir iktisadi eko-sistem oluşturabilir. Kapitalist finans ve iş modeli karşısında böylece güçlü bir alternatif geliştirilebilir.

İslam ekonomisi ve kurumlarının genel geçerliliğini sağlamak kapitalizmin sorunlarına bugün geliştirilecek kurumsal alternatiflerden geçmektedir. $\mathrm{Bu}$ nedenle muşaraka vakfı ve buna benzer modellerin ortaya konması, tartışılması ve uygulama imkanlarının araștırılması gerekmektedir. Önerilen model ulusal bir stratejiye dönüştürülerek Memleket Sandıkları projesi örneğinde olduğu gibi yaygınlaștırılabilir.

\section{Kaynakça}

Abdul Rahman, R., \& Dean, F. (2013). Challenges and solutions in Islamic microfinance. Humanomics, 29(4), 293-306.

Ahmed, H. (2002). Financing microenterprises: An analytical study of Islamic microfinance institutions. Islamic Economic Studies, 9(2), 27-64.

Alüftekin, N., Yüksel, Ö., Taş, A., Çakar, G., \& Bayraktar, F. (2012). Küresel krizden çıkışta kümelenme modeli: tekstil ve hazır giyim sektörü örneği. Uluslararası Yönetim Íktisat ve İşletme Dergisi, 5(10), 1-19.

Asutay, M. (2007). A political economy approach to Islamic economics: Systemic understanding for an alternative economic system. Kyoto bulletin of Islamic area studies, 1(2), 3-18.

Attar, F. (2012). Pendname. Çev. Mehmet Ali Özkan. Semerkand. İstanbul.

Babacan, M. (2011). Economics of Philanthropic Institutions, Regulation and Governance in Turkey. Journal of Economic and Social Research, 13(2), 61-89.

Battal, F. G. (2014). Türkiye'de havacıllk kümelenmeleri ve finansman sorunları. Niğde Üniversitesi İktisadi ve İdari Bilimler Fakültesi Dergisi, 7(1), 273.

Boz, Ç. (2018). Sürdürülebilir Kalkınmanın Bir Öncülü Olarak Keynes'in "İyi Yaşam” Felsefesi ve Kapitalizm Eleştirisi. Yildiz Social Science Review, 4(2), 187-200.

Bulut, M. (2015). Ahlak ve iktisat. ADAM AKADEMI Sosyal Bilimler Dergisi, 5(2), 105-123. 
Bulut, M., \& Korkut, C. (2016). A Comparison Between Ottoman Cash Waqfs (CWs) and Modern Interest-Free Financial Institutions. Vakıflar Dergisi, 46, 24-45.

Bulut, M. \& Korkut, C. (2019). Ottoman Cash Waqfs: an Alternative Financial System. Insight Turkey, 21(3), 91-111.

Cahill, D. (2014). The end of Laissez-Faire?: On the durability of embedded neoliberalism. Edward Elgar Publishing.

Chapra, M. U. (2011). The global financial crisis: can Islamic finance help?. In Islamic Economics and Finance (pp. 135-142). Palgrave Macmillan, London.

Chowdhury, M. S. R., bin Ghazali, M. F., \& Ibrahim, M. F. (2011). Economics of Cash WAQF management in Malaysia: A proposed Cash WAQF model for practitioners and future researchers. African Journal of Business Management, 5(30), 12155.

Cizakca, M. (1998). Awqaf in history and its implications for modern Islamic economies. Islamic Economic Studies, 6(1), 43-70.

David, F. (2009). Strategic Management Concepts and Cases, 12th Ed. Pearson Prentince Hall, USA.

Duménil, G., \& Lévy, D. (2011). The crisis of neoliberalism. Harvard University Press. USA.

Foster, J. B., \& McChesney, R. W. (2017). The endless crisis: How monopoly-finance capital produces stagnation and upheaval from the USA to China. Monthly Review Press.

Genç, M. (2018). Osmanlı İmparatorluğu'nda devlet ve ekonomi. Ötüken, İstanbul.

Grossberg, L. (2010). Modernity and commensuration: a reading of a contemporary (economic) crisis. Cultural studies, 24(3), 295-332.

Günay, A. (2008). Akılıkta Mesleksel Dayanışma, Yalın, İstanbul.

Gürsoy, Ç. (2014). Para Vakıfları Muhasebe Kayıtları Örneğinde Ahî-Esnaf Birlikleri, II. Uluslararası Harakani Sempozyumu Tebliğ, Kafkas Üniversitesi.

Hasan, Z., \& Abdullah, M. N. (2008). The Investment of Waqf Land as an instrument of Muslims: Economic development in Malaysia. The Dubai International Conference on Endowments' Investment, February (pp. 4-6).

Hassan, M. K., \& Kayed, R. N. (2009). The global financial crisis, risk management and social justice in Islamic finance. ISRA International Journal of Islamic Finance, 1(1), 33-58.

High, J. (1983). Knowledge, maximizing, and conjecture: a critical analysis of search theory. Journal of Post Keynesian Economics, 6(2), 252-264.

Ibrahim, H., Amir, A., \& Masron, T. A. (2013). Cash waqf: An innovative instrument for economic development. International Review of Social Sciences and Humanities, 6(1), 1-7.

Kala, A. (2019) Ahi Kümelenme Modeline Göre Anadolu Sanayi Devrimi, KuveytTürk Yayınları, İstanbul.

Kar, B. B. (2017). Keynes'te Kapitalizmin Ahlaki Eleştirisi. Ís Ahlakı Dergisi, 10(2), 275302.

Kara, M. (2009). Sosyal ve Kültürel Yapının Girişimcilik Üzerine Etkileri ve Türk Toplu- 
mundan Örnekler, Journal of Azerbaijani Studies, 465-485.

Kato, H. (2004). A Historical Study of the Market Society Reflected in the Waqf System in Muslim Societies (Special Issue: A Comparative Perspective on Asia: Market Economies). Annals of Japan Association for Middle East Studies, 20(1), 47-63.

Kotz, D. M. (2009). The financial and economic crisis of 2008: A systemic crisis of neoliberal capitalism. Review of Radical Political Economics, 41(3), 305-317.

Kuran, T. (2001). The provision of public goods under Islamic law: Origins, impact, and limitations of the waqf system. Law and Society Review, 841-898.

Lahsasna, A. (2010). The role of cash waqf in financing micro and medium sized enterprises (MMEs). Seventh International Conference-The Tawhidi Epistemology: Zakat and Waqf Economy (pp. 97-118).

Mohsin, I.A. M. (2013). Financing through cash-waqf: a revitalization to finance different needs. International Journal of Islamic and Middle Eastern Finance and Management, 6(4), 304-321.

More, T. (2017). Utopia, İstanbul: Oda.

Obaidullah, M. (2008). Introduction to Islamic Microfinance. New Delhi: IBF Net.

O'Donnell, R. (1990). The Epistemology of J. M. Keynes. The British Journal for the Philosophy of Science, 41(3), 333-350.

Overbeek, H., \& Van Apeldoorn, B. (2012). Neoliberalism in crisis. Springer.

Palley, T. I. (2010). The limits of Minsky's financial instability hypothesis as an explanation of the crisis. Monthly Review, 61(11), 28.

Riaz, S., Buchanan, S., \& Bapuji, H. (2011). Institutional work amidst the financial crisis: emerging positions of elite actors. Organization, 18(2), 187-214.

Saad-Filho, A. (2011). Crisis in neoliberalism or crisis of neoliberalism?. Socialist Register, 47(47).

Salarzehi, H., Armesh, H., \& Nikbin, D. (2010). Waqf as a social entrepreneurship model in Islam. International Journal of Business and Management, 5(7), 179.

Schoenblum, J. A. (1999). The Role of Legal Doctrine in the Decline of the Islamic Waqf: A Comparison with the Trust. Vand. J. Transnat'l L., 32, 1191.

Schumpeter, J. (1942). Creative destruction. Capitalism, socialism and democracy, 825.

Schumpeter, J. A. (2006). History of economic analysis. Routledge.

Siddiqi, M. N. (2009). Current financial crisis and Islamic economics. Insights, 1(3), 141.

Smolo, E., \& Mirakhor, A. (2010). The global financial crisis and its implications for the Islamic financial industry. International Journal of Islamic and Middle Eastern Finance and Management, 3(4), 372-385.

Tabb, W. K. (2012). The restructuring of capitalism in our time. Columbia University Press.

Williamson, O. E. (1993). Opportunism and its critics. Managerial and decision economics, 14(2), 97-107.

Zuki, M. S. M. (2012). Waqf and its role in socio-economic development. ISRA International Journal of Islamic Finance, 4(2), 173-178. 
